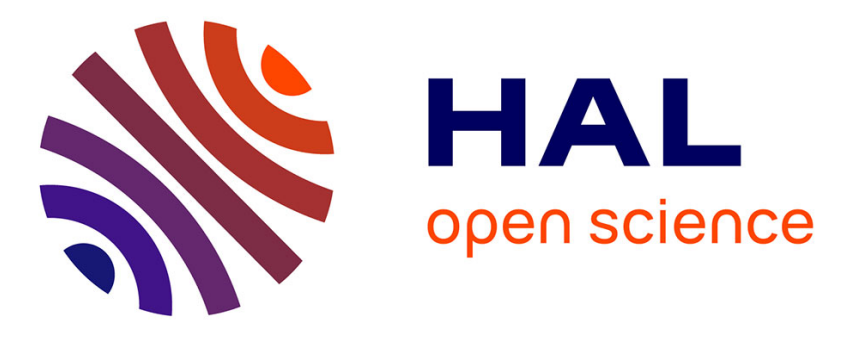

\title{
A New Method to Characterize Density Adapted to a Coarse City Model
}

\author{
Rachid Hamaina, Thomas Leduc, Guillaume Moreau
}

\section{To cite this version:}

Rachid Hamaina, Thomas Leduc, Guillaume Moreau. A New Method to Characterize Density Adapted to a Coarse City Model. Vasily Popovich; Christophe Claramunt; Manfred Schrenk; Kyrill Korolenko. Information Fusion and Geographic Information Systems (IF AND GIS 2013), Springer Berlin Heidelberg, 2014, 978-3-642-31832-0. 10.1007/978-3-642-31833-7_16 . hal-01347216

\section{HAL Id: hal-01347216 https://hal.science/hal-01347216}

Submitted on 20 Jul 2016

HAL is a multi-disciplinary open access archive for the deposit and dissemination of scientific research documents, whether they are published or not. The documents may come from teaching and research institutions in France or abroad, or from public or private research centers.
L'archive ouverte pluridisciplinaire HAL, est destinée au dépôt et à la diffusion de documents scientifiques de niveau recherche, publiés ou non, émanant des établissements d'enseignement et de recherche français ou étrangers, des laboratoires publics ou privés. 


\title{
A new method to characterize density adapted to coarse city model
}

\author{
Rachid Hamaina ${ }^{1}$, Thomas Leduc ${ }^{2}$, and Guillaume Moreau ${ }^{1}$ \\ 1 LUNAM Université, Ecole Centrale de Nantes, CERMA UMR CNRS 1563 \\ 1, rue de la Noë, BP 92101, 44321 Nantes Cedex 3, France \\ ${ }^{2}$ LUNAM Université, CNRS, CERMA UMR CNRS 1563 \\ 6, quai François Mitterrand, BP 16202, 44262 Nantes Cedex 2 - France \\ \{rachid.hamaina, thomas.leduc\}@cerma.archi.fr, \\ guillaume.moreau@ec-nantes.fr \\ http://www. cerma.archi.fr
}

\begin{abstract}
Density is probably one of the most used indicators to characterize urban development. Even if it is a quantitative and properly defined measure, there are still problems to use it properly. This paper proposes a renewed approach to characterize urban density based on buildings' footprints. It can be applied on huge datasets and allows multi-level characterization of density. We first present an original partition of urban open space. This topology helps us to define a neighborhood function. We then adapt the GSI and FSI indices to the previously defined tessellation. The combination of the neighborhood function and the modified indices makes it possible to assess density iteratively. For each building, these values allow to define density profile which is then used in a classification process. The results highlight spatial patterns and homogeneous areas. This transposable method is adapted to urban fabric characterization and surpasses old descriptive and low formalized classifications.
\end{abstract}

Keywords: density profile, extended FSI (Floor Space Index), extended GSI (Ground Space Index), open space tessellation, urban morphology

\section{Introduction}

3D city models are usually only available for the downtown area of cities or for small particular areas or for individual urban landmarks. Furthermore, these 3D city models are usually only used for visualization purposes.

However, a coarse 3D city model can easily be derived from traditional topographic databases. It can be achieved by extruding buildings footprints by their corresponding heights. Such a coarse model is poor for visualization applications. It can nevetheless be used in a GIS framework offering thus wide capabilities for urban analysis. Indeed, such coarse urban models have already been used to perform buildings type classification [1] or to simulate urban blocks densification $[2]$. 
Density is intensively used in urban geography, planning and design. It is defined as a concentration measure of certain entities in a given area. The commonly used entities in urban analysis are population, dwellings, services and jobs. Built-area (Floor space) density is perhaps the most used to characterize urban development and its regulation.

Density is often confused with building type. One assumes as an example, that detached houses are of lower density than attached housing types. While this is generally true it is not always the case. Also, a high-rise tower with large units set on a park-like area may be lower density than a set of detached houses on small lots [3]. In [4], a multivariable approach to density characterization is suggested. It uses four variables expressing intensity $\left(\mathrm{FSI}^{3}\right)$, compactness $\left(\mathrm{GSI}^{4}\right)$, pressure on non-built space $\left(\mathrm{OSR}^{5}\right)$ and building height (L: Layers).

However, since density is area-dependant, the well known Modified Area Unit Problem, MAUP [5], is unavoidable. Moreover, if the reference area is some spatial unit with a non enough formalized definition, just as are urban blocks and districts; the density measure can be of little relevance and can even be confusing.

When density indicators are used in descriptive (characterization) rather than prescriptive (normative) purposes, these are usually an aggregated measure over some administrative areas [6] or some regular division of urban space [7].

An alternative characterization of urban form patterns is based on the use of fractals. [8] uses the fractal dimension of built-up areas to characterize urban fabrics and concludes that this considers both morphology and internal structure while density gives just a rough idea of the occupation of the surface. However, this fractal measure considers neither the buildings 3D templates nor the neighboring open space morphology. Furthermore, it was pointed that the so-called fractal cities can be understood according to self-similarity in the sense of statistical analysis instead of pure theory and scaling invariance can be only defined within certain range of scales [9].

Here, we propose a new formulation of urban density characterization by integrating open space morphological characteristics and a weighted neighborhood aware density calculation.

To achieve this, we associate buildings footprints data to a surrounding open space's geometry. This open space partition, based on buildings geometry, allows measuring density indicators considering a reference area based on urban morphology and not on land ownership as traditionally done. This way, urban space anisotropy is taken into account.

This open space partition is a well formalized solution to identify minimum area unit around a given urban building. Indeed, as a pure geometric method, it is reproducible independently from urban context. Moreover, it also overcomes not only potential lack of plots data availability, but also potential spatial coverage problem between buildings and plots layers (frequent mismatch).

\footnotetext{
${ }^{3}$ Floor Space Index

${ }^{4}$ Ground Space Index

${ }^{5}$ Open Space Ratio
} 


\section{Methods}

In this section, a three-steps process is presented. The first one consists in defining a unique geometric item surrounding each building's footprint. This building's neighborhood, strongly related to the building item, makes it possible to partition the urban fabric. The partition method we present here has already been defined in [10].

In a second step, intensity (FSI) and compactness (GSI) are revised and a definition based on the new spatial-item (the building's neighborhood) is presented. Combining these extended GSI and FSI indices with the aforementioned neighborhood (at different distance levels), gives the possibility to define the density profile of a given building.

Finally, in a third step, buildings footprints of whole study area are classified into homogeneous sub-categories based on profile density characteristics. The performed classification is a weighted neighborhood aware classification since it takes into account GSI and FSI computed over several neighborhoods and weighted using a decreasing function.

\subsection{Open space tessellation}

Open space geometry Placing a new spatial object in a space induces change in the configurational properties of this space. In the urban environment, every new building (as a new external morphological item introduced in its spatial context) induces in its immediate neighborhood some morphology's change. It impacts the status with respect to several configurational parameters and physical phenomena (visibility, lighting, air circulation, movement, etc.) around the concerned building. The introduction of each new building corresponds to a spatial integration of a sort of new attractor. By analogy, using a gravity model concept (the attraction that objects have for each other is set against the distance they are apart), this new building inserts a new item (cell) in the whole set of partitions, a new item which can be delineated by a sort of skeleton through the open space between its neighbouring buildings.

This space tessellation based on the Euclidean distance between neighbouring buildings footprints is called a Voronoi diagram (see Fig. 1). Here, the tessellations represent some morphological influence cells corresponding to individual buildings in the urban space.

Let us assume that the contours of this space tessellation (a sort of urban open space skeleton) are the edges of a streets network. The same way, let us assume a pedestrian walk through the urban fabric using this (artificial) streets network; in each of the tessellation nodes, the walker will face substantial morphological changes. More precisely, these punctual locations correspond to most significant places in term of morphological changes.

The results of this tessellation are three new spatial objects: the nodes (0D) in the Voronoi diagram intersections that are the locations of significant change on morphology, the skeleton edges (1D) that are sort of developed artificial streets and the Voronoi diagrams (2D) that are the morphological influence cells. The 




Fig. 1. Buildings footprints and corresponding Voronoi diagrams in a given urban area (northern districts of Nantes city, France).

latter are considered here as some vital space all around each building (required to supply air and light) and by analogy with ownership based division, these are just like a sort of morphological plots.

Urban environmental conditions strongly depend on urban space morphology. As an example, the amount of air (ventilation) and natural lighting of buildings depend on the urban space openness and consequently on surrounding open space geometry. We believe that these new spatial items based on morphological characteristics are more pertinent (for morphological issues, at least) than the traditional ones based on administrative, ownership or other non-standardized partitions.

Neighbouring properties The Voronoi diagram partition topology allows defining a neighbouring function based on the shared borders (in the sense of a spatial intersection) of these polygons.

The function allows defining for each building "B" several neighborhoods (from 1 to $\mathrm{n}$ ) and several neighbours (buildings) for each neighborhood. This is based on spatial topologic relationships as following:

Let's $V=V_{1}, \ldots, V_{n}$ the set of Voronoi diagram cells corresponding respectively to the set of buildings $B=B_{1}, \ldots, B_{n}$ in a given urban area. $\mathrm{V}$ is a space partitioning of this area. 
Let's $\mathrm{NH}_{1}\left(B_{i}\right)$ be the first neighborhood of a building " $B_{i}$ " (the set of all adjacent cells) and $\mathrm{NB}_{1}\left(B_{i}\right)$ its first neighbours (the set of all corresponding buildings).

$$
\left.\begin{array}{c}
\text { if } V_{i} \cap\left\{V_{j}, V_{k}, \ldots, V_{m}\right\} \neq \varnothing \text { then } \\
\mathrm{NH}_{1}\left(B_{i}\right)=\bigcup\left\{V_{i}, V_{j}, V_{k}, \ldots, V_{m}\right\} \\
\text { and } \\
\mathrm{NB}_{1}\left(B_{i}\right)=\left\{B_{j}, B_{k}, \ldots, B_{m}\right\}
\end{array}\right\}
$$

The second neighborhood $\mathrm{NH}_{2}$ and neighbours $\mathrm{NB}_{2}$ of the building " $B_{i}$ " are iteratively constructed from equation (1) by replacing $V_{i}$ by $\mathrm{NH}_{1}$. The process is iterative and at the $\mathrm{n}^{\text {iest }}$ iteration, $\mathrm{NH}_{n}$ and $\mathrm{NB}_{n}$ are constructed from equation (1) by replacing $V_{i}$ by $\mathrm{NH}_{n-1}$.

$$
\left.\begin{array}{c}
\text { if } \mathrm{NH}_{n-1} \cap\left\{V_{j}, V_{k}, \ldots, V_{m}\right\} \neq \varnothing \text { then } \\
\mathrm{NH}_{n}\left(B_{i}\right)=\bigcup\left\{\mathrm{NH}_{n-1}, V_{j}, V_{k}, \ldots, V_{m}\right\} \\
\text { and } \\
\mathrm{NB}_{n}\left(B_{i}\right)=\left\{B_{j}, B_{k}, \ldots, B_{m}\right\}
\end{array}\right\}
$$

\subsection{Density characterization}

Modified GSI and FSI As written above, aim in this subsection is to benefit from building's neighborhood (as well-formalized spatial object) to revise FSI and GSI definitions. Thus, these two commonly used indicators in urban studies are transposed to the previously defined morphological plot. Even if these are traditional indicators, their calculation over artificial morphological plots (instead of administrative plots) gives them more relevance for urban morphology characterization purposes.

In our renewed approach, the GSI corresponds to the ratio between the building's footprint area and the corresponding Voronoi diagram's cell area. And the FSI is the ratio between the building's volume and the corresponding Voronoi diagram's cell area (see Fig. 2).

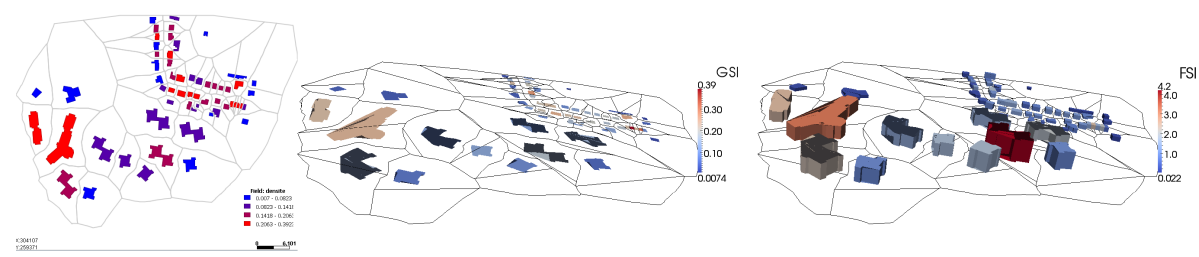

Fig. 2. Buildings density indicators: GSI (left and center) and FSI (right) in a small urban area. 
Density profiles Density indicators (GSI and FSI) are computed for each building and at different distance levels (that is over successive "i"-neighborhoods from $i=1$ to $\mathrm{n}$ ). At level zero, the only building's neighborhood is the one of the morphological plot itself, and corresponding densities have already been defined previously. And densities of a building "B" at the $\mathrm{i}^{\text {th }}$ neighborhood are:

$$
\begin{gathered}
\operatorname{GSI}_{i}(B)=\frac{\operatorname{area}(B)+\sum_{j=1}^{i} \operatorname{area}\left(\mathrm{NB}_{j}\right)}{\operatorname{area}\left(\mathrm{NH}_{i}\right)} \\
\operatorname{FSI}_{i}(B)=\frac{\operatorname{volume}(B)+\sum_{j=1}^{i} \operatorname{volume}\left(\mathrm{NB}_{j}\right)}{\operatorname{area}\left(\mathrm{NH}_{i}\right)}
\end{gathered}
$$

A Density profile for a building "B" is constructed by the variation of (GSI or/and FSI) over several neighborhoods (see Fig. 3).

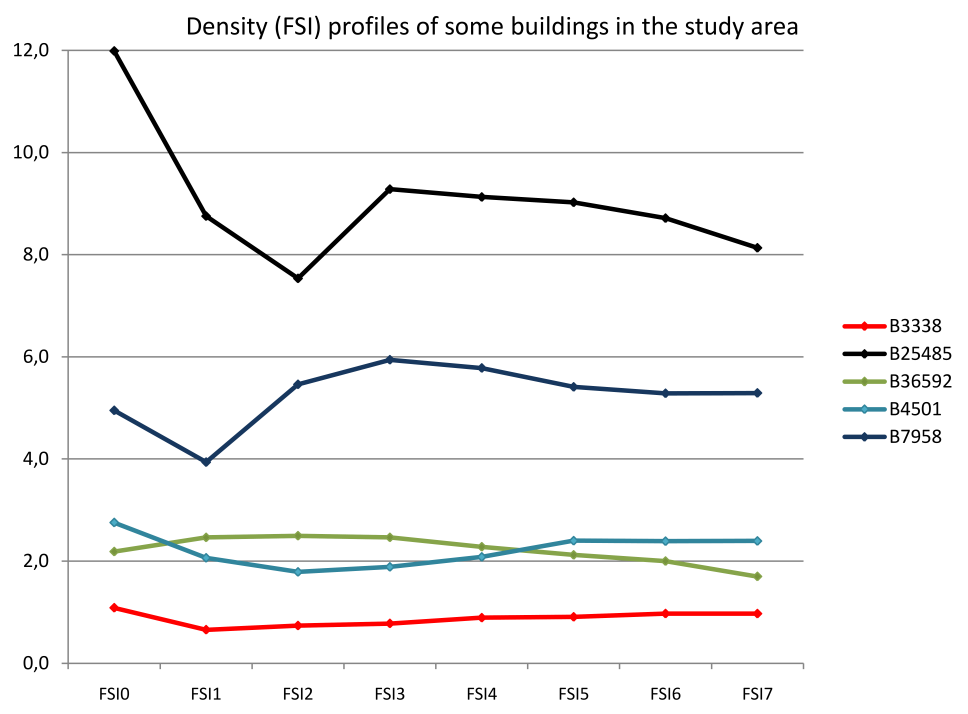

Fig. 3. FSI profiles (over seven neighborhoods) of a sample of five buildings.

Density profiles offer a useful tool to characterize local urban density based on morphologic characteristics and perhaps associate some particular profiles to some physical behaviour of the concerned buildings or group of buildings.

Taking into account neighborhood geometry (morphologic cells) and neighbouring buildings density is a key issue since each building influences its neighbours and is itself influenced by these. The characterization of individual buildings of an urban fabric is not sufficient to characterize the whole of the urban fabric itself. 


\subsection{Urban Classification based on density indicators}

For the classification of the buildings, we use a traditional k-means process using GSI and FSI over several neighborhoods. Thus, the input data of the clustering process is a matrix of dimensions $(2 n+2, \mathrm{~m})$ where $\mathrm{n}$ is the number of processed neighborhoods, $(2 n+2)$ is the number of variables and $m$ is the number of buildings footprint to classify.

GSI and FSI values are normalized and weighted following a decreasing function of the form $1 / x$ before being used in the classification (see Fig. 4). The 0.3679 factor is approximately equals to $\frac{1}{\sum_{i=1}^{8} \frac{1}{i}}$. It is built in such a way as to "normalize" the weighting function. The objective of the weighting process is to give less impact of neighbouring buildings on density as going away from the concerned building.

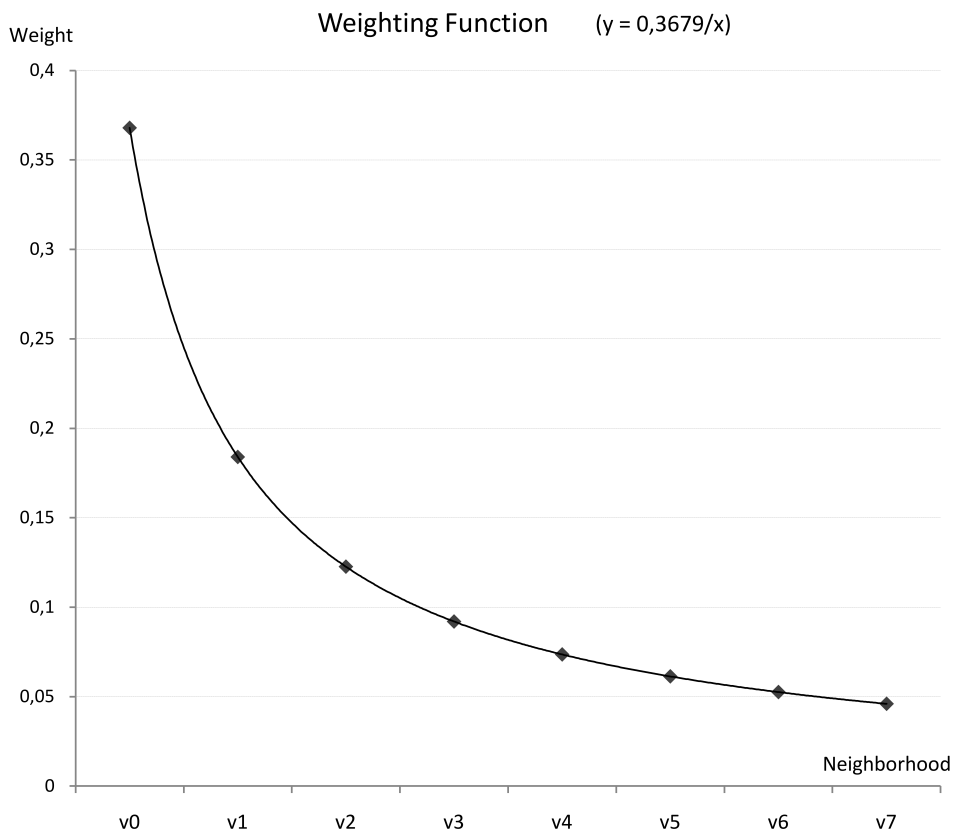

Fig. 4. The mathematical inverse function used for density weighting over successive (seven) neighborhoods.

\section{Results}

\subsection{Study area}

The study area is delineated by the beltway boulevard of Nantes city. Indeed, this freeway produces a physical (and functional) incision in the urban space 
and delimits therefore a homogeneous urban area in its interior. The only input data used are buildings footprints. These spatial data are derived from the topographic database provided by the French geographic institute (the so called BD TOPO $\left.{ }^{\circledR}\right)$.

\subsection{Density characterization}

Seven $(n=7)$ neighborhoods are processed. Fig. 5 and Fig. 6 respectively represent the results of GSI and FSI over the zero (the cell of the concerned building itself) and these 7 neighborhoods.

Density (both GSI and FSI) values in the zero's neighborhood are quite heterogeneous. This result is not surprising and it is expected because of the urban architecture and form diversity in cities in general and particularly in Nantes. At this local scale, it is difficult to highlight specific spatial patterns of density.

However, calculations over successive neighborhoods have a smoothing effect on local heterogeneity and gradually some spatial patterns can be recognized. This pattern is quite similar to the traditional gradient centre-periphery which is gradually becoming clearer when moving from the zero to $\mathrm{n}^{\text {th }}$ neighborhood, even if this is broken in many areas.

First, the rivers running in the study area and their watersheds break this gradient following four axes: an east-west axis (Loire river), a northern east axis (Erdre river), a southern axis (Sèvre river) and a northern west axis (Chézine river).

Then, some natural non-built areas located especially in the southern west (non-urbanized area) and in the northern east (recreational area) do the same exhibiting areas of very low density.

Because GSI is a 2D indicator while FSI is a 3D one, they don't follow exactly the same spatial pattern especially in the southeast and in some western parts of the study area. The former corresponds mostly to low rise housing areas (SaintSébastien sur Loire), which is why it exhibits high GSI values and low FSI ones. The latter is a high-rise buildings area (mostly large blocks), which is why it exhibits high values of FSI and low ones of GSI.

\subsection{Urban classification}

Urban density clusters Fig. 7 represents ten clusters resulting from the classification of the study's area buildings. These are organized from higher density to lower density areas.

Each cluster has different density characteristics from each other as shown by density profiles. However, for a better intelligibility of clusters typology, we group them into the traditional well known and used urban typologies.

Within the same group, various clusters (if this is the case) express some gradient on density and we can distinguish each of them even if no formalized descriptive definition is associated with each one. 


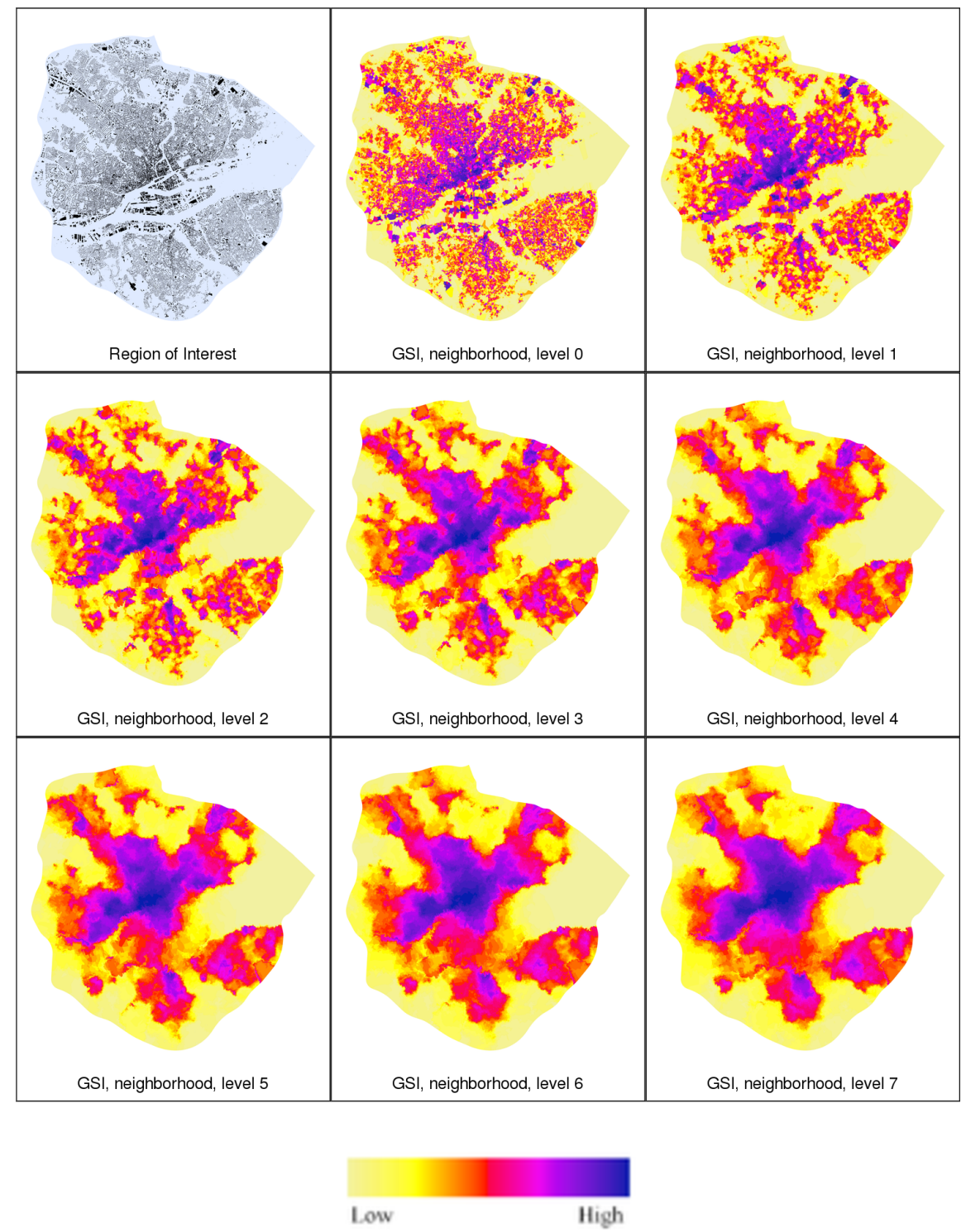

Fig. 5. GSI results in study area over the "zero" and seven successive neighborhoods. 


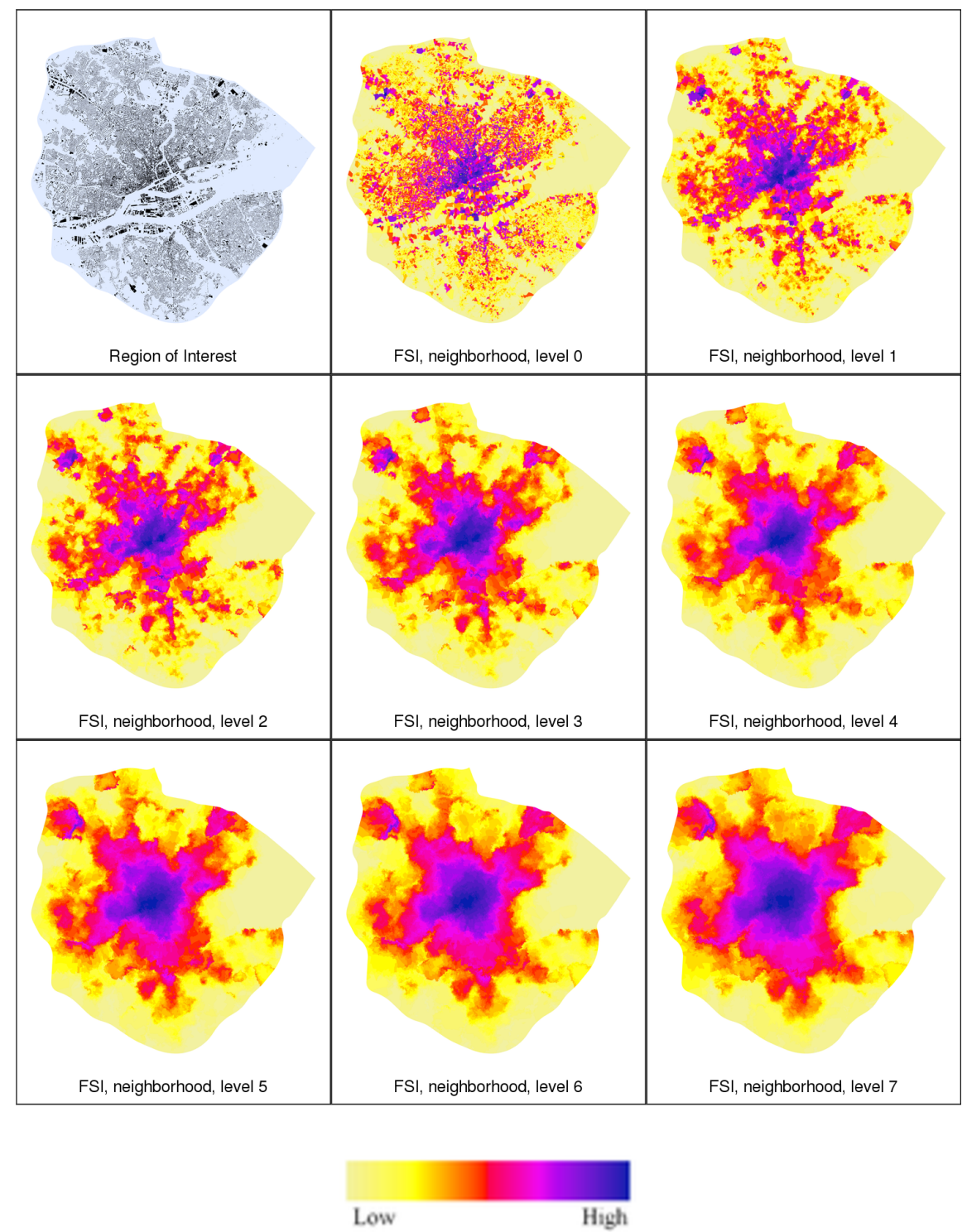

Fig. 6. FSI results in study area over the "zero" and seven successive neighborhoods. 

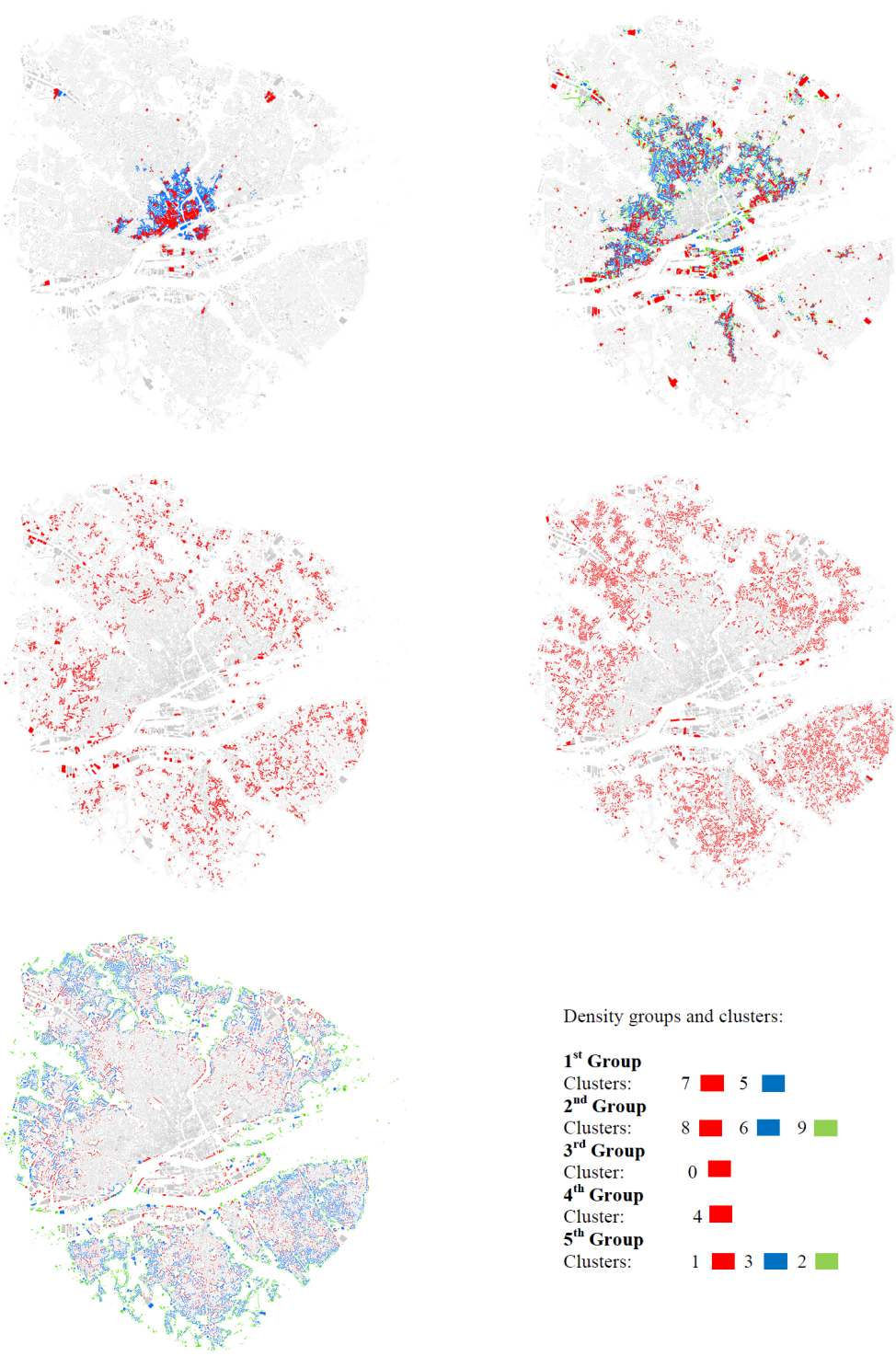

Fig. 7. Ten clusters grouped on five categories of urban density. 
So, the first group composed of the clusters 5 and 7 represent the down town, this is highly dense areas (organic historic centre). Cluster 7 is quite denser than cluster 5 because the latter includes areas which are adjacent to several open spaces as the cours des 50 otages's large avenue, and the Erdre and Loire rivers.

Very few industrial buildings are included in this group because they are enclosed by other large buildings creating thus for (only) these buildings a similar morphology to that of the city centre buildings.

The second group including the clusters 6, 8 and 9 is formed by downtown extensions until the first belt-way of the city, some industrial buildings (Ile de Nantes), few equipment buildings, linear facades (blocks) of some main (and thus dense) streets and few ancient hamlets cores. As in the first group, density is decreasing moving respectively from the cluster 8,6 and 9 .

The third group formed by the cluster 0 corresponds to medium density areas. These are mostly mid-rise areas (collective housing blocks), few equipment buildings and terraced individual houses.

The fourth group composed of the cluster 4 corresponds to low density areas. These include low-rise housing (mostly large individual houses) but also high-rise buildings set on park-like areas.

The last group composed of the clusters 1,2 and 3 corresponds to very low density areas. These include mostly low rise individual housing set on large open spaces.

Density clusters mean profiles For each cluster, a mean density (FSI and GSI) profile is processed. These are represented respectively in Fig. 8 and Fig. 9.

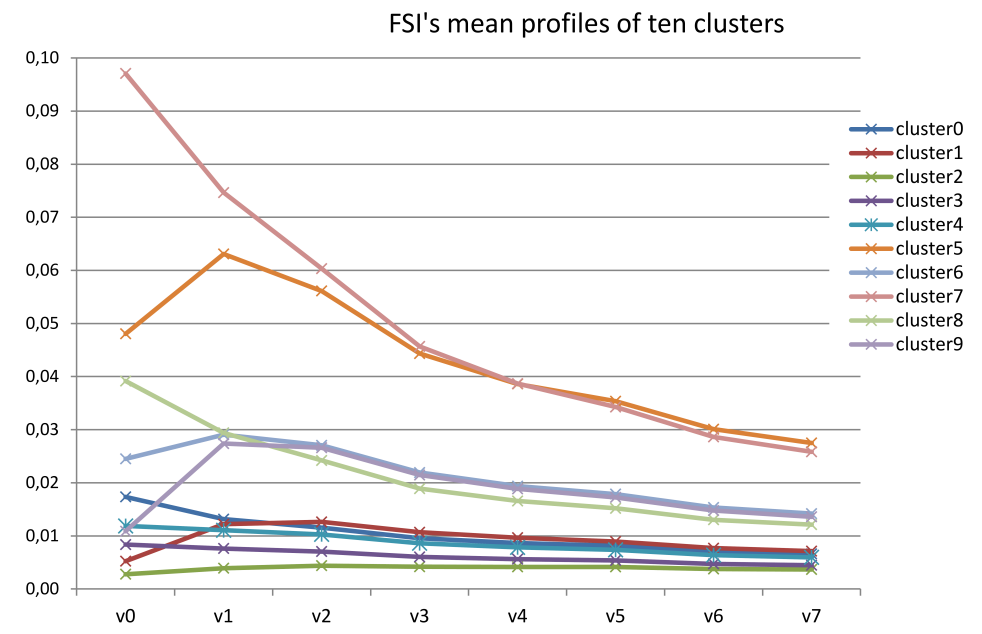

Fig. 8. FSI mean profiles of the ten clusters processed in the study area. 


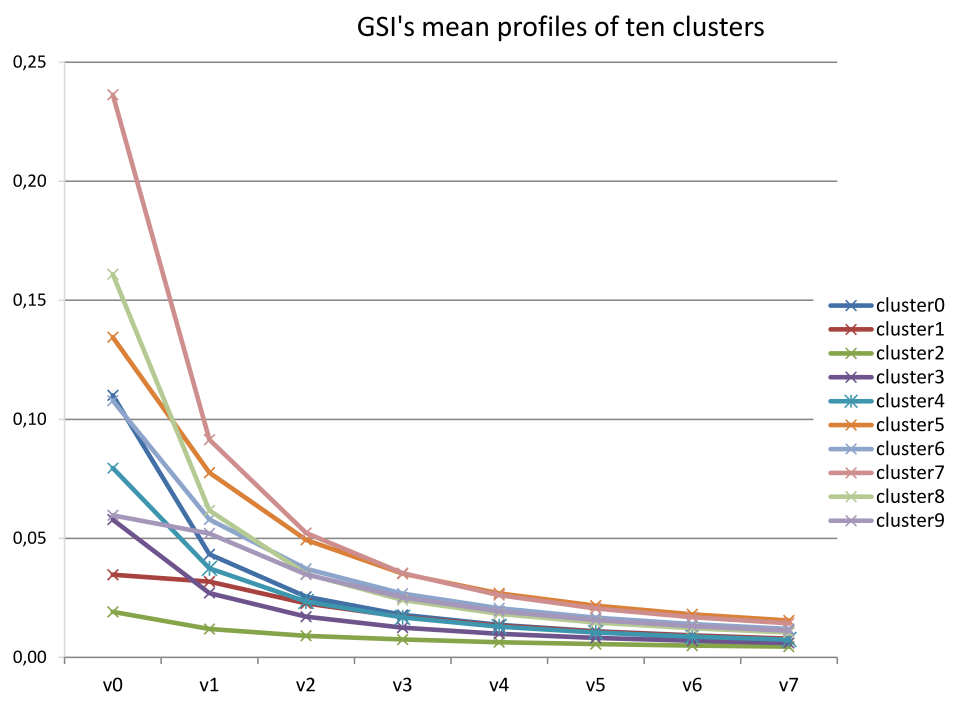

Fig. 9. GSI mean profiles of the ten clusters processed in the study area.

The most interesting finding from these mean density profiles is that the smoothing effect of the neighborhood's aware calculation of density represents an intelligent method of aggregation and grouping individual buildings on homogeneous density areas since the urban space is anisotropic.

Moving through successive neighborhoods, several profiles tend towards each other to form some groups. Nevertheless, even on advanced aggregation iteration (several neighborhoods used), the main three density categories: high density areas (down town), high to medium density areas (down town immediate extensions) and peripheral low density housing areas are still well distinguished. This is clearer in the FSI profile than in the GSI profile.

The first category is characterized by a fast decreasing density profile over successive neighborhoods. The second one is characterized by a moderate (slow) decreasing profile while the third category has a roughly constant profile.

\section{Conclusion}

This paper formalized a modified GSI and FSI based on a morphologic tessellation of urban open space. The topology of this tessellation allows defining a neighbouring function and process thus a density characterization taking into account several successive neighborhoods.

Densities computed over several neighborhoods allow the construction of density profiles of each building. Then, these individual buildings are classified according to density (GSI and FSI) values weighted by a decreasing function over neighborhoods. 
The results show that modified GSI and FSI profiles are useful tools for local characterization of density. Furthermore, the aggregation over neighborhoods as defined here is relevant for highlighting spatial patterns of density. And finally, the classification of individual buildings according to these modified density indicators highlights traditional urban fabric categories used in urban studies and allows performing even more detailed classification going beyond descriptive and low formalized urban classifications.

The density analysis developed here uses only a buildings footprints layer, it offers both local and aggregate density characterization and it can be performed on huge datasets in a GIS framework.

Regarding the legitimate domain, one can notice that the aforementioned method is relevant for any kind of urban areas. One of its main goal, is thus to delineate and classify urban fabrics.

Finally, it would be worth to compare numerically the resulting clusters with the results obtained using classical methods based on local averaging. Therefore, we should study GSI and FSI values using other partitioning techniques such as regular grid, building blocks, statistical units, etc (all methods that are less adaptative to local sample density).

\section{References}

1. Henn, A., Römer, C., Gröger, G., Plümer, L.: Automatic classification of building types in 3D city models. GeoInformatica 16(2) (July 2011) 281-306

2. Perret, J., Boffet Mas, A., Ruas, A.: Understanding urban dynamics: the use of vector topographic databases and the creation of spatio-temporal databases. In: 24th international cartography conference (ICC09), Santiago de Chile (2009)

3. Forsyth, A.: Measuring density: working definitions for residential density and building intensity. Design Brief (8) (2003) 8

4. Berghauser Pont, M., Haupt, P.: The relation between urban form and density. Urban Morphology 11(1) (2007) 62-66

5. Openshaw, S.: The modifiable areal unit problem. CATMOG - Concepts and Techniques in Modern Geography 38 (1983) 41

6. Smith, D.A., Crooks, A.T.: From buildings to cities: techniques for the multi-scale analysis of urban form and function. Technical Report 155, Centre for Advanced Spatial Analysis (UCL), London (2010)

7. Koomen, E., Rietveld, P., Bacao, F.: The third dimension in urban geography: the urban-volume approach. Environment and Planning B: Planning and Design 36(6) (2009) 1008-1025

8. Thomas, I., Frankhauser, P., De Keersmaecker, M.L.: Fractal dimension versus density of built-up surfaces in the periphery of Brussels. Papers in Regional Science 86(2) (June 2007) 287-308

9. Chen, Y.: Derivation of the functional relations between fractal dimension of and shape indices of urban form. Computers, Environment and Urban Systems 35(6) (November 2011) 442-451

10. Hamaina, R., Leduc, T., Moreau, G.: Towards Urban Fabrics Characterization based on Buildings Footprints. In Gensel, J., Josselin, D., Vandenbroucke, D., eds.: Bridging the Geographic Information Sciences. Lecture Notes in Geoinformation and Cartography. Springer Berlin Heidelberg, Berlin, Heidelberg (2012) 327-346 